\title{
Age-Associated and Cell-Type-Specific Neurofibrillary Pathology in Transgenic Mice Expressing the Human Midsized Neurofilament Subunit
}

\author{
James C. Vickers, ${ }^{1}$ John H. Morrison, ${ }^{1,2}$ Victor L. Friedrich, Jr., ${ }^{1,3}$ Gregory A. Elder, ${ }^{3}$ Daniel P. Perl, ${ }^{1,4,5}$ Robert N. \\ Katz, ${ }^{1}$ and Robert A. Lazzarini ${ }^{3}$ \\ ${ }^{1}$ Fishberg Research Center for Neurobiology, ${ }^{2}$ Department of Geriatrics and Adult Development, ${ }^{3}$ Brookdale Research \\ Center for Molecular Biology, ${ }^{4}$ Department of Pathology, and ${ }^{5}$ Department of Psychiatry, The Mount Sinai School of \\ Medicine, New York, New York 10029-6574
}

\begin{abstract}
Alterations in neurofilaments are a common occurrence in neurons of the human nervous system during aging and diseases associated with aging. Such pathologic changes may be attributed to species-specific properties of human neurofilaments as well as cell-type-specific regulation of this element of the cytoskeleton. The development of transgenic animals containing human neurofilament subunits offers an opportunity to study the effects of aging and other experimental conditions on the human-specific form of these proteins in a rodent model. The present study shows that mice from the transgenic line $\mathrm{NF}(\mathrm{M}) 27$, which express the human midsized neurofilament subunit at low levels $(2-25 \%$ of the endogenous NF-M), develop neurofilamentous accumulations in specific subgroups of neurons that are age dependent, affecting $78 \%$ of transgenic mice over 12 months of age. Similar accumulations do not occur in age-matched, wild-type littermates or in 3-month-old transgenic mice. In 12-month-old transgenic mice, somatic neurofilament accumulations resembling neurofibrillary tangles were present predominantly in layers III and V of the neocortex, as well as in select subpopulations of subcortical neurons. Intraperikaryal, spherical neurofilamentous accumulations were particularly abundant in cell bodies in layer II of the neocortex, and neurofilament-containing distentions of Purkinje cell proximal axons occurred in the cerebellum. These pathological accumulations contained mouse as well as human NF subunits, but could be distinguished by their content of phosphorylation-dependent NF epitopes. These cytoskeletal alterations closely resemble the cell-type-specific alterations in neurofilaments that occur during normal human aging and in diseases associated with aging, indicating that
\end{abstract}

\footnotetext{
Received Sept. 28, 1993; revised Mar. 11, 1994; accepted Mar. 24, 1994.

We express our gratitude to A. M. Edwards, W. Janssen, R. Woolley, S. Sun $X . L i$ and $S$. Lee for technical support, and to Drs. V. M.-Y. Lee, J. Q. Trojanowski, and $P$. Davies for the provision of antibodies. We also thank Drs. V. M.-Y. Lee J. Q. Trojanowski, and G. Huntley for critically reading the manuscript. This work was supported by Alzheimer's disease research grants from the American Health Assistance Foundation to both J.H.M. and R.A.L., and National Institute for Health Grants AG06647 (J.H.M.) and AG05138 (J.H.M., R.A.L.). J.C.V. is a recipient of a C. J. Martin Postdoctoral Fellowship from the Australian National Health and Medical Research Council.

Correspondence should be addressed to Dr. John H. Morrison, Fishberg Center for Neurobiology, Box 1065, Mount Sinai School of Medicine, One Gustave L. Levy Place, New York, NY 10029-6574, or Dr. Robert A. Lazzarini, Brookdale Research Center for Molecular Biology, Box 1126, Mount Sinai School of Medicine, New York, NY 10029-6574.

Copyright (C) 1994 Society for Neuroscience $0270-6474 / 94 / 145603-10 \$ 05.00 / 0$
}

these transgenic animals may serve as models of some aspects of the pathologic features of human neurodegenerative diseases.

[Key words: neurofilament, transgenic, cytoskeleton, aging, animal models, neurodegenerative disease]

Perturbations of neurofilaments (NFs) is a common pathologic feature of a variety of human neurodegenerative diseases, particularly those related to aging. These cytoskeletal elements have been shown to contribute to the formation of the neurofibrillary changes observed during normal human aging (Vickers et al., 1992) as well as in Alzheimer's disease (Dahl et al., 1982; Perry et al., 1985; Cork et al., 1986; Haugh et al., 1986; Miller et al., 1986; Lee et al., 1988b; Metuzals et al., 1988; Mulvihill and Perry, 1989; Zhang et al., 1989; Cammarata et al., 1990; Schmidt et al., 1990; Gheuns et al., 1991; Vickers et al., 1992), Lewy body-type dementias (Sima et al., 1986; Schmidt et al., 1991 Pollanen et al., 1992), Pick's disease (Perry et al., 1987; Ulrich et al., 1987), Parkinson's disease (Goldman et al., 1983; Forno et al., 1986; Bancher et al., 1989; Schmidt et al., 1991; Galloway et al., 1992), and amyotrophic lateral sclerosis (Manetto et al., 1988; Munoz et al., 1988; Toyoshima et al., 1989). Animal models of neurofilamentous pathology would facilitate analysis of the cellular and functional consequences of this type of cytoskeletal alteration. Established experimental models have included intoxication of animals with substances such as colchicine, aluminum, $\beta, \beta^{\prime}$-iminodipropionitrile, ethanol, acrylamide, and hexacarbons. Studies have also shown that aging and certain diseases in nonhuman animals result in neurofilamentous alterations in particular groups of neurons (van den Bosch de Aguilar and Goemaere-Vanneste, 1984; Cork et al., 1988a,b) with important similarities and differences to the neuropathologic hallmarks described in the above human diseases.

Interspecies variability in the cxtent of cytoskeletal pathology may be due to molecular differences between homologous neuronal intermediate filament proteins. Among the three subunits that comprise the coexpressed class of neuronal intermediate filaments known as the NF "triplet," the middle-molecularweight subunit, NF-M, is of particular interest since there are important molecular differences in the homologous subunit between species. For example, the human NF-M subunit contains a tandem array of 12 near-perfect repeats, each encoding a lysine-serine-proline-valine (KSPV) sequence (Myers et al., 1987), and it has been shown that this series of KSPVs can be phos- 


\begin{tabular}{lll}
\hline Table 1. & Neuronal markers \\
Antibody & Type & Reactivity \\
\hline SMI32 & MM & mouse/human nonphos NF-M/NF-H \\
SMI310 & MM & mouse/human phos $(+++$ ) NF-M/NF-H \\
RMO108 & MM & mouse phos( + ) NF-M \\
HO14 & RM & human phos(+++) NF-M \\
Alz50 & MM & A68 protein \\
AB1690 & RabP & ubiquitin \\
13814311 & RabP & $\beta$-amyloid
\end{tabular}

MM, mouse monoclonal; RM, rat monoclonal; RabP, rabbit polyclonal; nonphos, nonphosphorylated epitope; phos $(+)$, partially phosphorylated epitope; $\operatorname{phos}(+++)$, highly phosphorylated epitope.

phorylated and forms the major antigenic site of the NF-M subunit (Geisler et al., 1987; Lee et al., 1988a). Rodent and avian NF-M subunits, while otherwise very similar to their human counterpart, contain only one or two degenerate KSPV repeats (Levy et al., 1987; Napolitano et al., 1987; Zopf et al., 1987). Furthermore, the squid neurofilament gene, which is thought to be more primitive than the vertebrate gene, encodes an NF-M without KSPV repeats (Way et al., 1992). These observations suggest that the multiple repeats of this motif are a phylogenetically recent addition to the NF-M protein, occurring after the divergence of rodent and primate orders. These differences may be important pathologically since abnormal phosphorylation has been suggested to be a general mechanism leading to cytoskeletal alterations in human disease, and so the differences in organization of this phosphorylation site repeat region in the NF-M carboxy terminus may be contributing to the propensity of NFs to undergo disease/age-related alterations. Indeed, phosphorylation of the repeat-containing region of human NF-M in the presence of $\mathrm{Ca}^{2+}$ or $\mathrm{Al}^{3+}$ produces dramatic conformational changes that lead to NF aggregation, including cross-linking and a high content of $\beta$-pleated sheet structure (Hollósi et al., 1992).

The production of transgenic mice expressing human neurofilament proteins (Charron et al., 1992; Lee et al., 1992; Côté et al., 1993) presents an opportunity to study the specific human isoform of these cytoskeletal proteins within a rodent model that is amenable to aging and experimental studies. The previously characterized NF(M)27 transgenic mouse line is particularly useful as this mouse expresses the human NF-M subunit at levels substantially lower (2-25\%) than those of the native murine NF-M, but with the human subunit contributing toward the formation of normal filaments in young animals (Lee et al., 1992). Using multiple immunohistochemical markers and electron microscopy, we have found that these animals exhibit a striking age-associated pathology involving the accumulation of neurofilamentous material into pathologic structures that not only resemble those found in human diseases but also display similar patterns of cellular vulnerability that may be linked to cell-type-specific regulation of NF protein content and metabolism.

\section{Materials and Methods}

Animals. The NF(M)27 transgene contains an $8.5 \mathrm{~kb}$ DNA fragment that includes the human NF-M gene and an $2.8 \mathrm{~kb}$ upstream promoter sequence. Mice heterozygous for the NF(M)27 transgene express the human protein in the CNS and PNS, with immunoelectron microscopy demonstrating that the human NF-M protein coassembles into filaments with the endogenous mouse NF proteins (Lee et al., 1992).
Heterozygous transgenic and wild-type littermate control mice were bred on a mixed $\mathrm{C}_{57} \mathrm{Bl} / 6 \mathrm{~J}$, DBA $/ 2 \mathrm{~J}$ background and the presence of the transgene was determined for each individual by PCR analysis of blood or tail DNA. This study used 3- and 12-month-old heterozygous and wild-type littermate control mice. A limited analysis was also performed on tissue from the line's founder mouse, aged 27 months, and from other transgenic and wild-type mice between the ages of 4 and 8 months.

Immunohistochemical analysis. Under anesthesia (ketamine/xylazine), mice were perfused intracardially initially with a $0.1 \mathrm{M}$ phosphatebuffered saline solution followed by $4 \%$ paraformaldehyde in phosphatebuffered saline. The brain and spinal cord were removed and postfixed in the paraformaldehyde solution for $4 \mathrm{hr}$. Thirty-micrometer cryostat sections were collected for immunohistochemistry, including sagittal and coronal sections of the right and left halves, respectively, of the brain rostral to the level of the inferior colliculus, along with coronal sections of the remaining brainstem and cerebellum and transverse sections of the spinal cord.

A variety of antibodies to NF proteins and other pathological markers (Table 1) were visualized using either species-specific Vectastain ABC immunoperoxidase kits (Vector Lab., Burlingame, CA) or secondary antibodies conjugated to the fluorophores fluorescein isothiocyanate (FITC) or Texas red (Vector and Amersham, Arlington Heights, IL). Secondary antibodies were free of undue cross-reactivity. Mouse monoclonal antibodies SMI32 and SMI310, which respectively recognize nonphosphorylated or phosphorylated epitopes on both human and mouse NF-M and NF-H subunits (Lee et al., 1988a; Zhang et al., 1989), were obtained from Sternberger Monoclonals Inc. (Baltimore, MD); RMO108, a mouse monoclonal antibody that recognizes partially phosphorylated mouse NF-M (Lee et al., 1987; Pleasure et al., 1990), and HO14, a rat monoclonal antibody that labels phosphorylated human NF-M (Lee et al., 1987, 1988a; Pleasure et al., 1990), from V. M.-Y. Lee (University of Pennsylvania School of Medicine); Alz50, from P. Davies (Albert Einstein College of Medicine, NY); AB1690 (anti-ubiquitin), from Chemicon (Temecula, CA); and 13814311 (anti- $\beta$-amyloid), from Boehringer Mannheim (Indianapolis, IN). Some of the sections labeled with FITC were counterstained either with DAPI $(4,6-$ diaminodino-2-phenylindole) or ethidium bromide, fluorescent markers for nuclear DNA and cytoplasmic RNA, respectively. Sections from the above animals were also stained with thioflavine $S$, a histochemical marker for the neurofibrillary tangles and senile plaques of Alzheimer's disease.

Ultrastructural analysis. Blocks of tissue corresponding to the frontal pole of the cerebral cortex of one 12-month-old transgenic animal were postfixed in $1 \%$ glutaraldehyde overnight, osmicated, and embedded in an Araldite resin. Thin $(65 \mathrm{~nm})$ sections were cut on a Reichert microtome, mounted on Formvar-coated grids, stained with uranyl acetate, and examined with a Hitachi 7000 electron microscope.

\section{Results}

Immunolabeling with antibodies that recognize nonphosphorylated (SMI32) and phosphorylated (SMI310) epitopes on both mouse and human NF-M and NF-H subunits (Lee et al., 1988a; Zhang et al., 1989) was present in the nervous system of both transgenic and wild-type mice at 3 and 12 months of age. SMI32 preferentially labeled neuronal perikarya and dendrites with minimal axonal labeling (Fig. $1 \mathrm{~A}$ ), whereas SMI310 preferentially labeled axons. Another antibody, RMO108, that recognizes partially phosphorylated NF-M mouse epitopes but not human NF proteins (Lee et al., 1987; Pleasure et al., 1990) labeled cell bodies, dendrites, and axons in transgenic and wildtype mice of both ages. Specific subpopulations of neurons were labeled with RMO108 and SMI32 throughout the mouse brain in a pattern that was consistent with the restricted distribution of the neurofilament triplet proteins to particular neuronal subtypes (reviewed in Vickers and Costa, 1992a). Labeling with the antibody specific for human NF-M phosphorylated epitopes (HO14) (Lee et al., 1987, 1988a; Pleasure et al., 1990) was present in axons of transgenic animals as previously described (Lee et al., 1992), whereas no labeling was present in wild-type mice. 

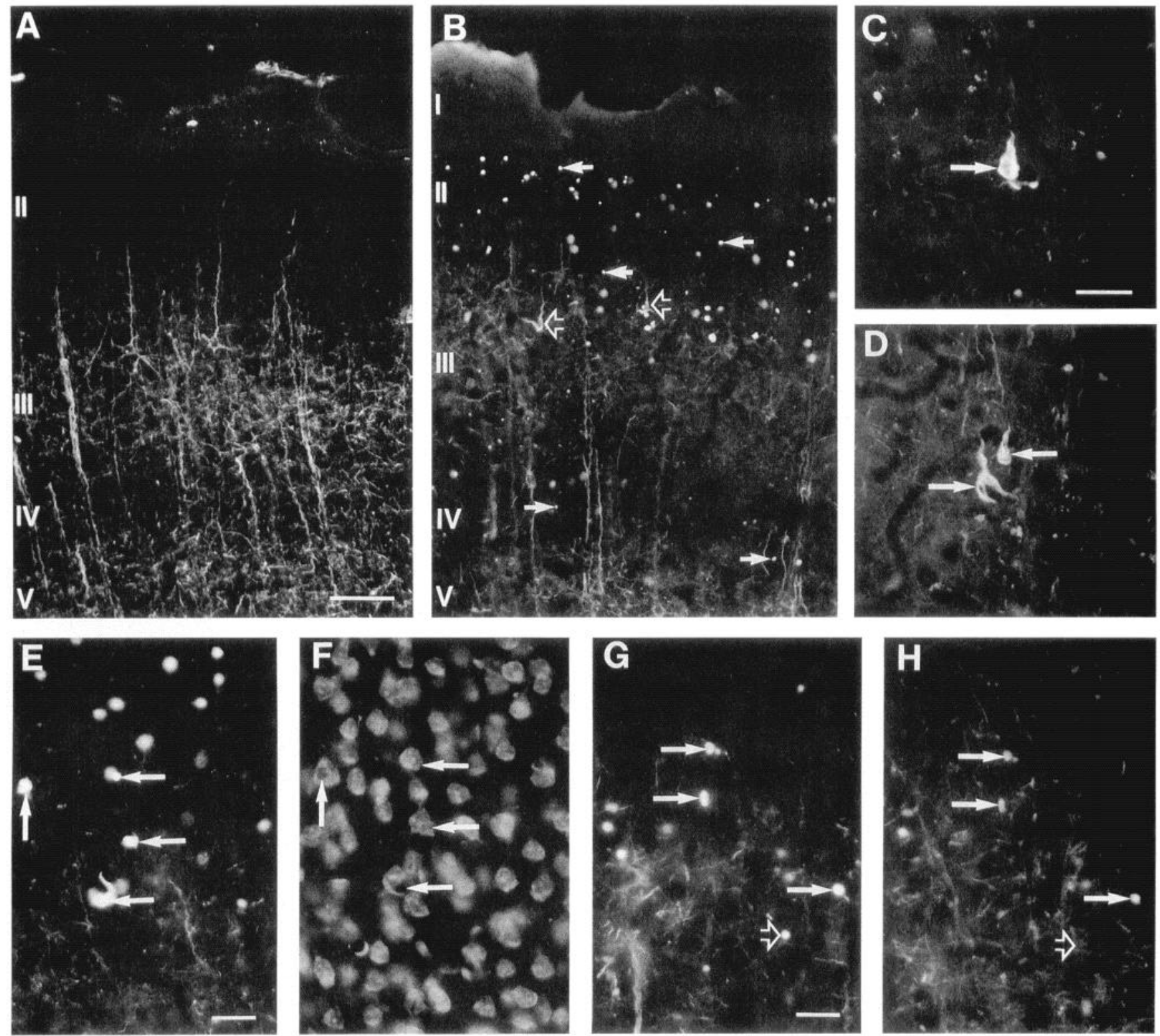

Figure 1. NF immunolabeling in the cerebral cortex of wild-type and transgenic animals. $A$ and $B$, Examples of SMI32 (nonphosphorylated NF-M and NF-H) labeling in the somatosensory cortex of 12-month-old wild-type $(A)$ and transgenic $(B)$ mice. Solid arrows in $B$ show examples of spherical NFAs in layers II and IV, whereas open arrows demonstrate tangle-like NFAs in layer III. $C$ and $D$, Higher-power micrographs of tanglelike NFAs in layer $\mathrm{V}$ of the frontal $(C)$ and somatosensory cortex $(D)$ of 12 -month-old transgenic mice. $E$ and $F$, Double labeling for SMI32 and ethidium bromide (RNA marker) in layer II of the somatosensory cortex, with arrows showing examples of NFAs within cell bodies. $G$ and $H$, Double labeling for SMI32 $(G)$ and HO14 (human phosphorylated NF-M proteins) $(H)$ in layer II of frontal cortex. Many of the spherical NFAs are labeled for both SMI32 and HO14 (solid arrows), whereas some of SMI32 labeled NFAs lack HO14 labeling (open arrows). Scale bars: $A$ and $B, 100 \mu \mathrm{m} ; C-H, 25 \mu \mathrm{m}$.

SMI32 and RMO108 also intensely labeled neurofilamentous accumulations (NFAs) present in the nervous system of six of the eight 12-month-old transgenic animals examined, but not in five age-matched wild-type mice or in 50 3-month-old transgenic mice. The same pathologic structures were visualized equally well with immunofluorescence and immunoperoxidase cytochemical procedures. The NFAs consisted of two basic morphological types: (1) tangle-like perikaryal accumulations surrounding or adjacent to the nucleus and tapering off into the primary dendritic processes, and (2) spherical or ellipsoidal structures, varying in diameter from approximately 1 to $10 \mu \mathrm{m}$. The spherical NFAs were particularly prevalent in the neocortex
(Figs. $1 B-H, 2$ ), with fewer of these inclusions in the amygdala, thalamus, hippocampus (Fig. $3 A$ ), and cerebellum, whereas tangle-like NFAs were observed in neocortex (Figs. $1 B-D, 2 A$ ) but were also present in the hippocampus (Fig. $3 A$ ), entorhinal cortex, amygdala, thalamus (Fig. $3 B$ ), superior colliculus, pontine nuclei, deep cerebellar nuclei, gracile nucleus, cuneate nucleus, inferior olivary nucleus, some reticular neurons, and cranial nerve nuclei such as the cochlear, vestibular, trigeminal motor, facial motor, and hypoglossal nuclei (Fig. 3D,E).

With regard to the neocortex, tangle-like NFAs were distributed primarily in layers III and V, whereas the relatively more abundant spherical NFAs were present principally in layer II 
A
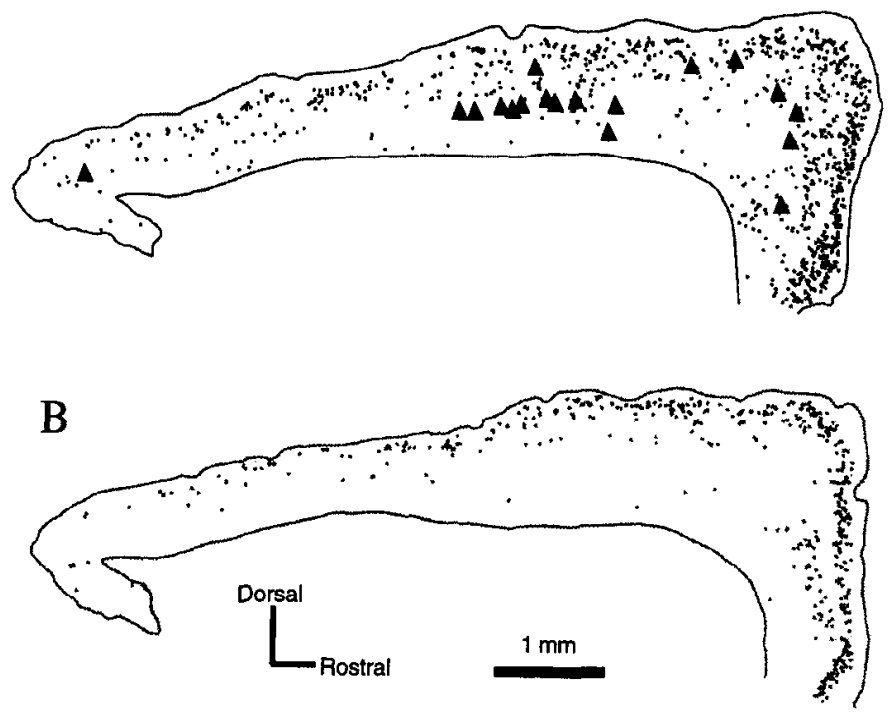

Figure 2. Distribution of NFAs in the cerebral cortex: examples of maps of the pathological structures present in sagittal sections of the mouse neocortex. Maps were derived from captured digital images and custom morphometry software developed at the Fishberg Research Center for Neurobiology (New York, NY) and the Scripps Research Institute (La Jolla, CA). A, The location of SMI32-labeled spherical NFAs (*), which are principally located in layer II, and tangle-like NFAs (A) located in layers III and V. $B$, The location of the spherical NFAs $\left(^{*}\right)$ labeled with HO14 in a sagittal section of the neocortex. Relatively few of these pathologic features are located in caudal regions of the cortex.

and, to a lesser degree, layer IV (Figs. $1 B-H, 2$ ). Both the spherical and tangle-like NFAs were predominantly located in somatosensory and frontal neocortex, including the motor areas, with relatively few of these NFAs occurring in visual cortex. While the pattern of NFA formation in the cortex was qualitatively similar between these animals, there was considerable variation in the number of these structures present in a given area. For example, the density of spherical NFAs in layers II and III of somatosensory cortex was $60.0( \pm 6.6 \mathrm{SE}), 51.0( \pm 9.9)$, and $19.4( \pm 4.6)$ per millimeter of cortical traverse in the three most severely affected transgenic animals to less than five per millimeter in the three other animals showing these cytoskeletal alterations. Similarly, tangle-like NFAs varied from 15-20 per sagittal section in the severely affected animals to one or two per section in the least affected animals. Cortical sections from the 12-month-old transgenic mice labeled with SMI32 or RMO108 and counterstained with either DAPI or ethidium bromide demonstrated that the great majority of the tangle-like and spherical NFAs occurred inside cell bodies (Fig. $1 E, F$ ).

The cortical spherical NFAs were labeled by SMI32, RMO108, SMI310, and HO14, indicating the presence of mouse and human NF-M, as well as nonphosphorylated and phosphorylated epitopes (Table 2). Double labeling verified that the phosphorylated form of the transgenic human protein, visualized with HO14, was present in a large subset of the spherical NFAs labeled with either SMI32 or RMO108 (Fig. $1 G, H$ ). Tangle-like NFAs were also vividly labeled by SMI32, indicating the presence of abundant nonphosphorylated NF-M and/or NF-H, but they differed from the spherical NFAs in that they were seldom $(<5 \%)$ labeled with antibodies (SMI310 and HO14) to either mouse or human phosphorylation-dependent epitopes (Table
Table 2. Reactivity of neurofilamentous accumulations (NFAs) with neurofilament markers

\begin{tabular}{lllll} 
& SMI & RMO & \\
& 32 & 108 & SMI310 HO14 \\
\hline Cortical tangle-like NFAs & + & + & - & - \\
Cortical spherical NFAs & + & + & + & + \\
Hippocampal perikaryal NFAs & + & + & $+/-$ & $+1-$ \\
Purkinje cell perikaryal NFAs & + & + & - & - \\
Purkinje cell axonal NFAs & + & + & + & + \\
Brainstem perikaryal NFAs & + & $+/-$ & - & -
\end{tabular}

+ , positive immunoreactivity; - , negative immunoreactivity, $+/-$, both immunoreactive and nonimmunoreactive NFAs in particular region.

2). Thus, in contrast to the tangle-like NFAs, many of the spherical NFAs contained phosphorylation-dependent NF protein epitopes normally found in axons.

In the cerebellum of the 12-month-old transgenic mice, NFAs labeled with NF antibodies were present in less than $1 \%$ of Purkinje cell bodies (Fig. 3C, Table 2). Some Purkinje cells demonstrated swellings of the proximal axon that were labeled with SMI32, RMO108, HO14, and SMI310. No NFAs were observed within other cell types of cerebellar cortex.

Ultrastructural analysis of the frontal pole of a 12-month-old transgenic animal confirmed that many neurons in the superficial layers contained perikaryal accumulations of ultrastructurally identifiable neurofilaments that were likely to correspond to the spherical NFAs observed with immunocytochemical methods. These NFAs consisted of bundles of filaments that were often interconnected by fine filamentous cross-bridges (Fig. 4). Other cytoplasmic elements, such as mitochondria and tubular and vesicular membranes, as well as granular material were often detected within the NFAs.

No aberrant neurofilamentous structures were detected with these NF antibodies in the spinal cord of any of the animals, which is consistent with the low degree of expression of the human protein in this region in this line (Lee et al., 1992). Staining with thioflavine $S$ or immunolabeling with markers such as Alz50 and antibodies to $\beta$-amyloid and ubiquitin was not present in NFAs, or in any other structures specific to the 12-month-old transgenic animals.

As noted above in the case of the relative density of NFAs in the cortex of the older transgenic mice, individual variation occurs in the amount of neurofibrillary pathology. Furthermore, two of the eight 12-month-old transgenic animals lacked NFAs, although labeling with $\mathrm{HO} 14$ confirmed the presence of the human protein within axonal pathways characteristic of other animals of the NF(M)27 line (Lee et al., 1992). Abundant tanglelike and spherical NFAs, labeled with SMI32 and stained with silver impregnation methods, were also present in cortical sections of the 27-month-old NF(M) 27 founder, but NFAs have not been detected in a large group (50) of transgenic mice less than 3 months old. The presence of pathologic features at intermediate ages was variable, with spherical and tangle-like NFAs being observed in a 4.6-month-old transgenic animal but not in two 8-month-old transgenic mice examined.

\section{Discussion}

The data presented in this report demonstrate that the neurofilamentous inclusions in NF(M)27 mice are linked to the presence of the human NF gene and are age dependent, suggesting 

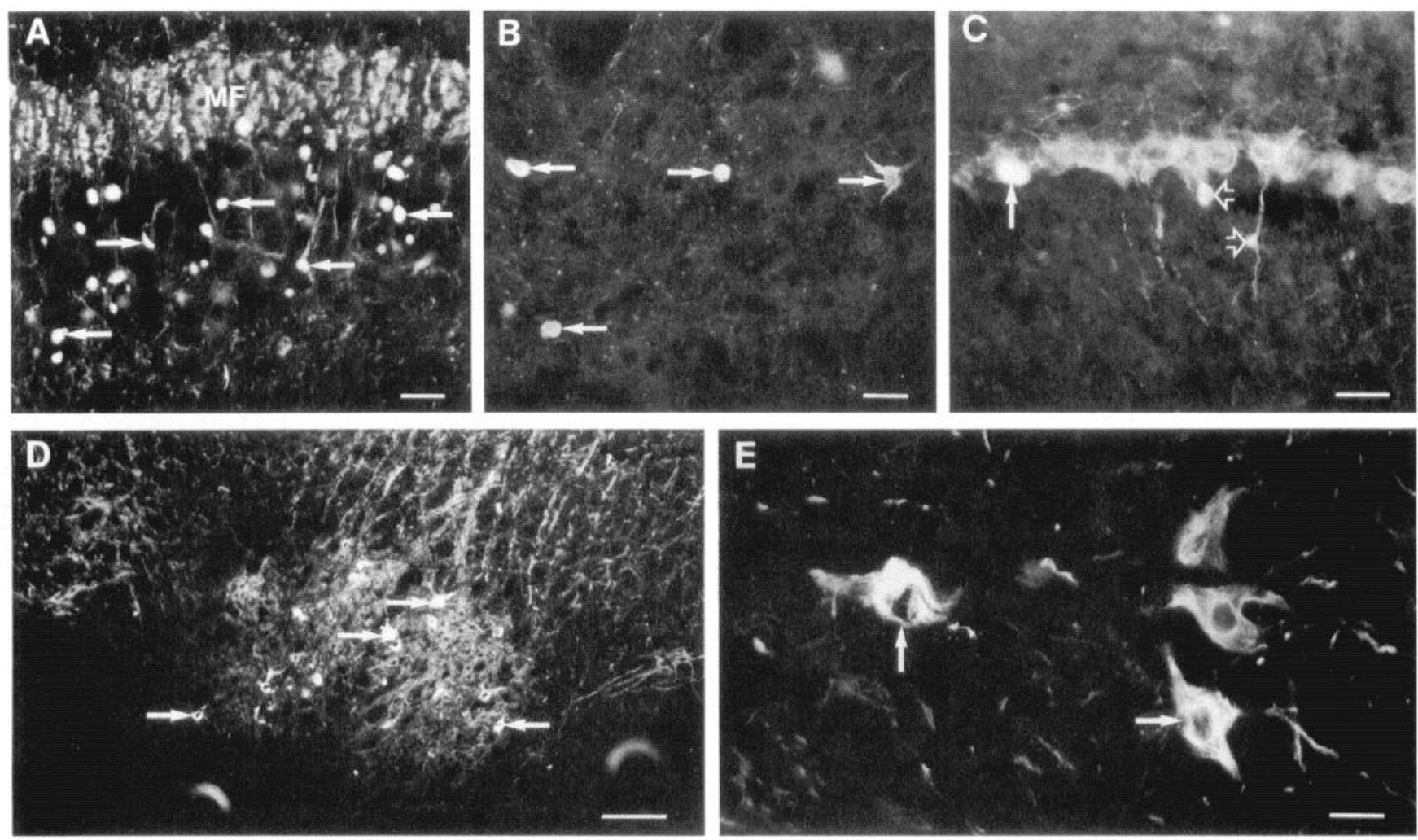

Figure 3. Immunolabeling of subcortical structures in the transgenic mice: immunofluorescent labeling for NF proteins in the hippocampus $(A)$, thalamus $(B)$, cerebellum $(C)$, and brainstem cranial nerve motor nuclei $(D, E)$ of 12-month-old transgenic mice. Arrows in $A$ indicate examples of NFAs labeled with RMO108 (mouse-specific NF-M) in the pyramidal cell layer of the CA3 region in the hippocampus (MF, mossy fibers). Arrows in $B$ show NFAs in the dorsal lateral geniculate nucleus labeled with SMI32. $C$, SMI32 labeling in the cerebellum. NFAs are present within Purkinje cell bodies (solid arrows) and axons (open arrows). D, An example of SMI32 labeling in the facial nerve nuclei, with arrows indicating examples of neurons with NFAs. Trigeminal motor neurons $(E)$ also develop NFAs (arrows) in these transgenic mice. Scale bars: $A-C, 25 \mu \mathrm{m} ; D$, $100 \mu \mathrm{m} ; E, 15 \mu \mathrm{m}$.

a number of similarities with cytoskeletal perturbations that occur in the human nervous system due to aging and diseases associated with aging. Inappropriate processing, degradation, and/or overproduction of the human NF protein in the transgenic mice may be possible mechanisms leading to cytoskeletal alterations. Indeed, relatively young transgenic mice expressing high levels (two to four times the level of the endogenous subunit) of either human NF-H (Côté et al., 1993) or the endogenous NF-L proteins (Xu et al., 1993) have been shown to develop accumulations of NFs in spinal motor neurons that resemble the pathologic features of human motor neuron disease. However, in $\mathrm{NF}(\mathrm{M}) 27$ mice, gross overexpression of NF protein may be unlikely to be the cause of NFA formation since the transgenic human NF-M was shown to be present at very low levels (2$25 \%$ ) relative to the level of the endogenous murine NF-M (Lee et al., 1992). The brain areas showing these neurofilamentous changes were among those that were previously demonstrated to contain relatively higher amounts of the human NF-M protein $(12-25 \%$ of the endogenous NF-M), whereas no NFAs were detected in the spinal cord, which appears to contain little human NF-M (approximately $2-3 \%$ of the endogenous NF-M). Future studies will examine whether there may be an age-related upregulation of human NF-M expression or an increase in protein levels that may account for the accumulation of NFs in these neurons. Conversely, there is a large body of evidence demonstrating age-related changes in neurofilaments in the human nervous system, suggesting that species-specific characteristics of the human NF protein in this transgenic line may cause heightened susceptibility to age-related cellular processes that in turn lead to alterations in the normal neurofilamentous cytoskeleton. Interestingly, while many of the older transgenic animals showed these neurofilamentous changes, the relative density of the NFAs varied between animals of the same age, which may be indicative of the complex age-related mechanisms that affect neurons. Similarly, Alzheimer's disease-like pathology appears to be selective for certain subpopulations of neurons and affects particular cytoskeletal proteins, and yet there is great variability in the distribution of the neurofibrillary pathology that occurs during normal human aging (Bouras et al., 1993) and Alzheimer's disease (Arnold et al., 1991).

Many of the NFAs in the transgenic animals also closely resembled, both ultrastructurally and immunohistochemically, similar filamentous inclusions that occur in animal models of aluminum toxicity (Terry and Pena, 1965; Dahl and Bignami, 1978; Kowall et al., 1989; Gilbert et al., 1992). Notably, neocortical pyramidal neurons in layers III and V were selectively vulnerable to form tangle-like NFAs in both the transgenic animals and aluminum-intoxicated rabbits (Kowall et al., 1989). However, these rabbit filamentous inclusions contained phosphorylation-dependent NF epitopes, whereas the tangle-like NFAs in NF(M)27 mice lacked such epitopes.

\section{Is pathologic heterogeneity in $N F(M) 27$ mice related to cell-type-specific processing of NFs?}

There is increasing evidence that different subpopulations of neurons contain and regulate the intermediate filament protein 

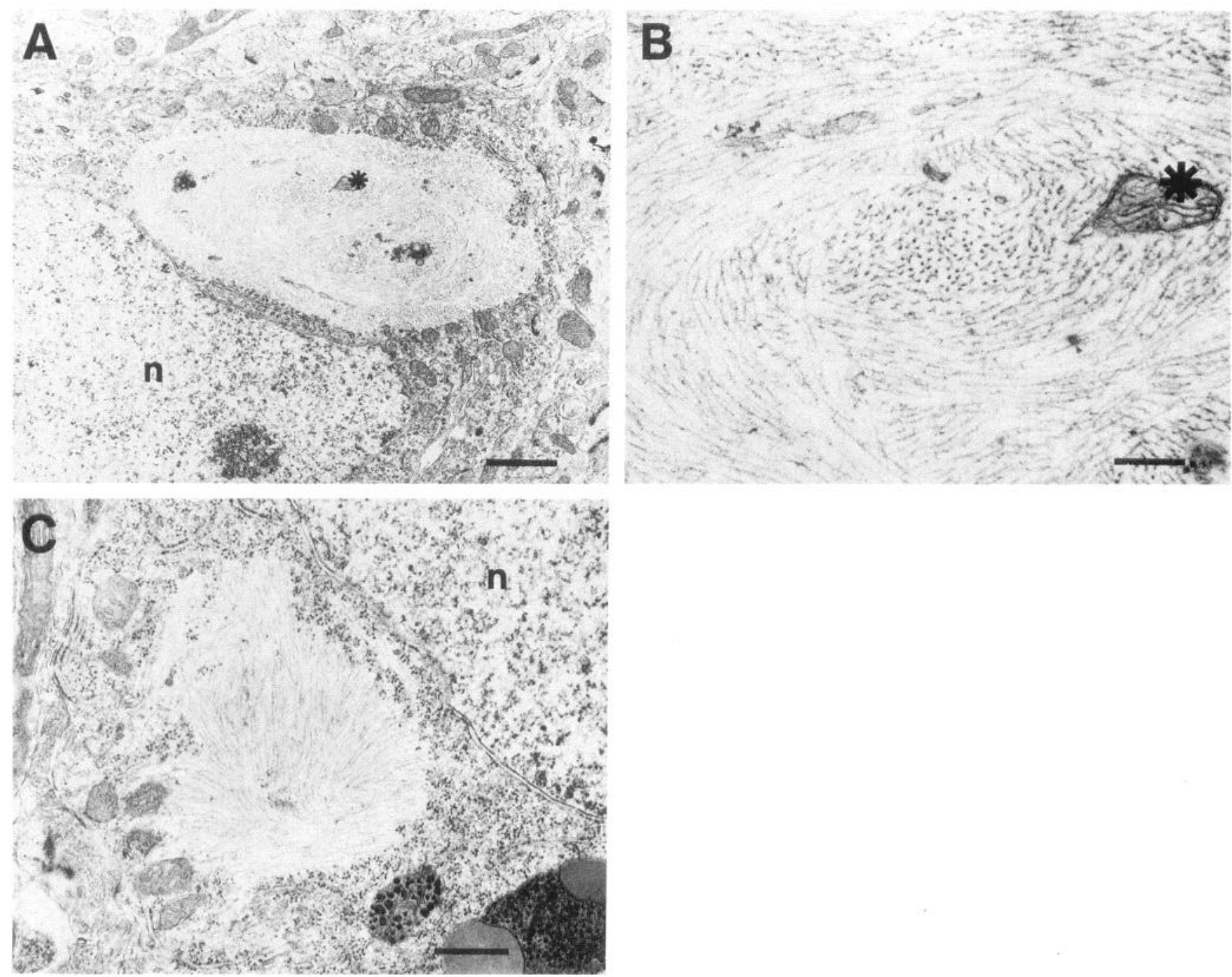

Figure 4. Fine structure of spherical NFAs in the frontal pole of a transgenic animal. $A$, An NFA is located in the cytoplasm near the nucleus ( $n$ ) of a neuron. Surrounding the NFA are organelles of normal appearance. $B$, Higher magnification of $A$ showing bundles of neurofilaments within the NFA (asterisk marks the same mitochondrial profile in $A$ and $B$ ). Filaments approximately $10 \mathrm{~nm}$ in diameter. $C$, A second inclusion showing filaments radiating from the center of the NFA. Scale bars: $A, 1 \mu \mathrm{m} ; B, 200 \mathrm{~nm} ; C, 500 \mathrm{~nm}$.

component of their cytoskeleton differentially. A number of different proteins can comprise mammalian neuronal intermediate filaments, including the three related proteins known as the NF triplet as well as the $66 \mathrm{kDa}$ protein $\alpha$-internexin (Pachter and Liem, 1985; Chiu et al., 1989) and the $57 \mathrm{kDa}$ protein peripherin (Portier et al., 1984; Leonard et al., 1988; Parysek and Goldman, 1988). The NF triplet subunits are largely coexpressed (Shaw, 1991), are likely to be obligatory heteropolymers (Lee et al., 1993), and are present in specific subpopulations of neurons throughout the nervous system, which can vary or be conserved in homologous groups of neurons among mammalian species (reviewed in Vickers and Costa, 1992a). Biochemical studies have even shown differences in NF triplet content in the ventral tegmental area between strains of rats (Guitart et al., 1992). Neuron-specific molecular heterogeneity of neuronal intermediate filaments can also occur. For example, for most NF triplet-containing neurons, phosphorylation of the carboxy terminal domain of NF-M and NF-H occurs in the axon. However, different neuronal subpopulations can vary in the degree to which their axonal NFs are phos- phorylated (Oblinger et al., 1988; Szaro et al., 1990), and specific subgroups of neurons in sympathetic ganglia (Vickers and Costa, 1992b), retina (Shaw and Weber, 1984; Vickers and Costa, 1992a; Peichl and González-Soriano, 1993), peripheral sensory ganglia (Lawson et al., 1984; Berglund and Ryugo, 1986; Romand et al., 1988; Vickers and Costa, 1991), the mesencephalic sensory ganglion of the trigeminal nerve (Poltarak and Freed, 1987), and septofimbrial and triangular septal nuclei (Klosen et al., 1992) have been shown to contain phosphorylated NF epitopes in their cell body that are commonly found in axons. In addition, specific epitopes linked to the conformation of the extreme carboxyterminal domain of NF-M are differentially present in cell body and axonal domains of particular NF triplet-containing neurons (Vickers et al., 1990; Harris et al., 1991; Vickers and Costa, 1992a,b; Eaker et al., 1993).

These studies indicate a remarkable specificity in distribution and regulation of neuronal intermediate filament proteins that is consistent with the view that the neurofilamentous cytoskeleton is more dynamic than previously thought (Steinert and Liem, 1990; Nixon and Sihag, 1991; Shaw, 1991; Skalli et al., 
1992; Vickers and Costa, 1992a; Nixon, 1993) and may have cell-type-specific roles that are dependent on a configuration of both protein content and subsequent modifications. Consistent with this notion are observations that indicate that alterations in NFs can occur as a function of influences on neurons such as deafferentation (Shaw et al., 1988), specific excitatory amino acid receptor agonists (Wang et al., 1992), diabetes (Burnstock et al., 1988), thyroid deficiency (Marc et al., 1986), social deprivation (Siegel et al., 1993), morphine and cocaine (BeitnerJohnson et al., 1992), ethanol (Guru et al., 1991), myelination (de Waegh et al., 1992), and even temperature in the case of poikilothermic vertebrate species (Potter, 1975). Similarly, the neurofilamentous cytoskeleton may show particular vulnerability to processes associated with aging and related disease processes, although the precise pathologic consequences may be cell-type-specific and depend on how NFs are regulated in each particular neuron type. For example, the selective distribution of the NF triplet to particular cortical neurons has been hypothesized to underlie the vulnerability of neurons to form the neurofibrillary tangle of Alzheimer's disease (Morrison et al., 1987; Hof et al., 1990; Vickers and Costa, 1992a; Vickers et al., 1992).

The heterogeneous forms of NFAs observed in the transgenic mice may also be due to cell-type-specific regulation of the cytoskeleton, which may indicate why these inclusions are strikingly similar to the specific forms of neurofibrillary pathology observed in different human neurodegenerative diseases. For example, the NF(M) 27 mouse line mirrors the selective sensitivity of human neocortical neurons in Alzheimer's disease in that the mouse NF triplet-containing pyramidal neurons in layers III and V were the most vulnerable to form tangle-like NFAs, and these tangles were labeled with an antibody that recognizes nonphosphorylated NF protein, a feature shared with the early transitional form of the human neurofibrillary tangle (Vickers et al., 1992). In addition, the neurofilamentous aggregations often extended into the apical and basal dendrites, which followed the normal distribution of neurofilament immunoreactivity into these dendritic domains in certain pyramidal cells, and resembled in part the dendritic neurofibrillary pathology that is often associated with tangle formation (Braak and Braak, 1988). However, the tangle-like NFAs in these mice differed from neurofibrillary tangles in Alzheimer's disease in many respects. Anatomical discrepancies exist in terms of the relatively few tangle-like NFAs observed in the entorhinal cortex of the older NF(M) 27 mice, which is one of the earliest and most devastated sites of neurofibrillary pathology in Alzheimer's disease (Vickers et al., 1992). Mouse tangle-like NFAs were also unlabeled with thioflavine $S$ or antibodies to ubiquitin and the neurofibrillary tangle marker, Alz50. Neurofibrillary tangles found in humans may have undergone further maturation than those represented in NF(M) 27 mice. Further studies will determine whether the mousc tangle-like NFAs may lead to alterations of mouse tau proteins, and the degree to which specific experimental manipulations can lead to the formation of the NFAs in the transgenic mice that mirror the human pathologic profiles more precisely.

The NF(M) 27 mouse line may also serve as a model for, and provide some insight into, dementing disorders other than $\mathrm{Al}$ zheimer's disease. For example, both Pick's disease and Lewy body-type dementias are characterized by the presence of spherical inclusion bodies that occur within cortical layers that contain nonpyramidal and small pyramidal neurons, and the Pick and Lewy bodies are composed of filamentous material that can be labeled with NF antibodies (Sima et al., 1986; Dickson et al., 1987; G. Perry et al., 1987; Ulrich et al., 1987; R. H. Perry ct al., 1990; Schmidt et al., 1991; Pollanen et al., 1992). The spherical NFAs that occur in the NF(M)27 mouse line are therefore very similar in their laminar location, morphology, and neurofibrillary ultrastructure to both the cortical Lewy body and Pick body. In addition, the spherical NFAs of the transgenic mice and the Pick bodies in pathological human specimens both predominate in frontal cortex. Interestingly, the spherical NFAs were localized to cortical layers that usually lack NF tripletcontaining neurons (Vickers and Costa, 1992a), and mouse NF proteins were also immunohistochemically detected in these cortical NFAs. Induction of mouse NF protein expression in these cells may represent a response to human NF expression, a phenomenon previously noted for models of keratin expression in transfected cells (Giudice and Fuchs, 1987). The presence of NF triplet subunits in the cortical neurons that normally do not contain, or contain low amounts of, these proteins may thereforc be a causative factor lcading to the formation of the spherical NFAs within perikarya, indicating a possible pathway by which the cortical spherical inclusions present in human diseases may occur. Thus, induction or misprocessing of NF triplet proteins in some of the neurons that are not normally equipped to incorporate such proteins into their cytoskeleton and/or transport them into more distal processes may finally result in an accumulation of NFs and interconnected cytoskeletal elements in the cell body.

The alterations in NFs observed in the cerebellum indicate a further cell-type-specific perturbation of the cytoskeleton. A small minority of Purkinje cells were observed to have intraperikaryal accumulations and/or distentions of the proximal axon, which could be further distinguished by their differential labeling with antibodies that recognize phosphorylation-dependent epitopes. No other neuronal cell type was observed to have such axonal changes. The Purkinje cell axonal NFAs are very similar to the NF-containing, proximal axonal distention known as the "torpedo" (Hirano, 1991) that has been observed in numerous diseases involving cerebellar degeneration. These accumulations may therefore represent a Purkinje cell-specific consequence of neurofilament perturbation.

Abnormal phosphorylation of NFs has been linked with the formation of the filamentous hallmarks of numerous human neurodegenerative diseases. Thus, phosphorylation of the human NF-M subunit beyond that of murine NF-M may play a role in the development of NFAs in the transgenic mice. The torpedo-like axonal swellings in the cerebellum and the spherical NFAs of the cortex were labeled with phosphorylation-dependent NF antibodies. Ultrastructurally, the cortical spherical NFAs were shown to be composed of bundles of NFs with fine crosslinks. This ordered appearance is very similar to that normally observed for NFs in axons and it will be important to pursue the possibility that this organization may be related to the phosphorylation state of the NF subunits. However, most of the cortical tangle-like NFAs and subcortical perikaryal NFAs did not contain an immunodetectable increase in phosphorylation of either the human or mouse NF subunits. Detailed investigation of early stages of NFA formation may clarify the role of phosphorylation in the development of these NFAs. Recently, it has been proposed that neurofibrillary tangle formation in Alzheimer's disease involves the initial alteration of perikaryal nonphosphorylated NF proteins followed by the further trans- 
formation of these filaments into pathological structures, which is, in turn, associated with phosphorylation (Vickers et al., 1992). Thus, NFAs in the transgenic mice and the human neurofibrillary pathologic structures involving NFs may result from an initial perturbation in the normal neurofilamentous cytoskeleton followed in some cases by abnormal phosphorylation.

\section{Conclusions}

The presence and heterogeneity of NFA formation in the older $\mathrm{NF}(\mathrm{M}) 27$ mice may be linked to an interaction between agingrelated cellular processes and the specific molecular features of human NF-M, as well as to the different ways in which specific neuronal subpopulations regulate their cytoskeleton, and may in turn indicate similar mechanisms that may be occurring in human degenerative diseases. This may be particularly important in the context of the plasticity of these cytoskeletal elements and the possible reversibility of neurofilamentous changes, as demonstrated in models of aluminum-mediated neurofilamentous accumulations (Gilbert et al., 1992). Indeed, our doublelabeling experiments suggest that many of the NFAs observed in the transgenic mice were found in otherwise intact cells, which is very similar to the observations that the transitional forms of the human neurofibrillary tangle are largely intracellular as well (Vickers et al., 1992). This transgenic animal model may also be utilized to elaborate the consequences of such pathological changes in NFs for cellular function, neural circuitry, and behavior.

\section{References}

Arnold SE, Hyman BT, Flory J, Damasio AR, Van Hoesen GW (1991) The topographical and neuroanatomical distribution of neurofibrillary tangles and neuritic plaques in the cerebral cortex of patients with Alzheimer's disease. Cereb Cortex 1:103-116.

Bancher C, Lassmann H, Budka H, Jellinger K, Grundke-Iqbal I, Iqbal K, Wiche G, Seitelberger F, Wisniewski HM (1989) An antigenic profile of Lewy bodies: immunocytochemical indication for protein phosphorylation and ubiquitination. J Neuropathol Exp Neurol 48: 81-93.

Beitner-Johnson D, Guitart X, Nestler EJ (1992) Neurofilament proteins and the mesolimbic dopamine system: common regulation by chronic morphine and chronic cocaine in the rat ventral tegmental area. J Neurosci 12:2165-2176.

Berglund AM, Ryugo (1986) A monoclonal antibody labels type II neurons of the spiral ganglion. Brain Res 383:327-332.

Bouras C, Hof PR, Morrison JH (1993) Neurofibrillary tangle densities in the hippocampal formation in a non-demented population define subgroups of patients with differential early pathologic changes. Neurosci Lett 153:131-135.

Braak H, Braak E (1988) Neuropil threads occur in dendrites of tanglebearing nerve cells. Neuropathol Appl Neurobiol 14:39-44.

Burnstock G, Mirsky R, Belai A (1988) Reversal of nerve damage in streptozotocin-diabetic rats by acute application of insulin in vitro. Clin Sci 75:629-635.

Cammarata S, Mancardi G, Tabaton M (1990) Formic acid treatment exposes hidden neurofilament and tau epitopes in abnormal cytoskeletal filaments from patients with progressive supranuclear palsy and Alzheimer's disease. Neurosci Lett 115:351-355.

Charron G, Beaudet L, Côté F, Houle D, Julien J-P (1992) Regulation of the human neurofilament light and heavy genes in transgenic mice. In: Gene transfer and therapy in the nervous system (Gage FH, Christen Y, eds), pp 201-208. Bcrlin: Springer.

Chiu F-C, Barnes EA, Das K, Haley J, Socolow P, Mascaluso FP, Fant $J$ (1989) Characterization of a novel 66-kDa subunit of mammalian neurofilaments. Neuron 2:1435-1445.

Cork LC, Sternberger NH, Sternberger LA, Casanova MF, Struble RG, Price D (1986) Phosphorylated neurofilament antigens in neurofibrillary tangles in Alzheimer's disease. J Neuropathol Exp Neurol 45: 56-64.
Cork LC, Troncoso JC, Klavano GG, Johnson ES, Sternberger LA, Sternberger NH, Price DL (1988a) Neurofilamentous abnormalities in motor neurons in spontaneously occurring animal disorders. $\mathrm{J}$ Neuropathol Exp Neurol 47:420-431.

Cork LC, Powers RE, Selkoe DJ, Davies P, Geyer JJ, Price DL (1988b) Neurofibrillary tangles and senile plaques in aged bears. J Neuropathol Exp Neurol 47:629-641.

Côté F, Collard J-F, Julien J-P (1993) Progressive neuronopathy in transgenic mice expressing the human neurofilament heavy gene: a mouse model of amyotrophic lateral sclerosis. Cell 73:35-46.

Dahl D, Bignami A (1978) Immunochemical cross-reactivity of normal neurofibrils and aluminum-induced neurofibrillary tangles. Immunofluorescence study with antineurofilament serum. Exp Neurol 58:74-80.

Dahl D, Selkoe DJ, Pero RT, Bignami A (1982) Immunostaining of neurofibrillary tangles in Alzheimer's senile dementia with a neuroflament antiserum. J Neurosci 2:113-119.

de Waegh SM, Lee VM-Y, Brady ST (1992) Local modulation of neurofilament phosphorylation, axonal caliber, and slow axonal transport by myelinating Schwann cells. Cell $68: 451-463$.

Dickson DW, Davies P, Mayeux R, Crystal H, Horoupian DS, Thompson A, Goldman JE (1987) Diffuse Lewy body disease. Acta Neuropathol (Berl) 75:8-15.

Eaker EY, Sallustio JE, Harris JM, Shaw G (1993) Myenteric plexus neurons have developmentally acquired differences in the medium molecular weight subunit of neurofilament protein. Neuroscience 53: 561-570.

Forno LS, Sternberger LA, Sternberger NH, Strefling AM, Swanson K, Eng LF (1986) Reaction of Lewy bodies with antibodies to phosphorylated and non-phosphorylated neurofilaments. Neurosci Lett 64:253-258.

Galloway PG, Mulvihill P, Perry G (1992) Filaments of Lewy bodies contain insoluble cytoskeletal elements. Am J Pathol 140:809-821.

Geisler N, Vandekerckhove J, Weber K (1987) Location and sequence characterization of the major phosphorylation sites of the high molecular mass neurofilament proteins $M$ and $H$. FEBS Lett 221:403407.

Gheuns J, Cras P, Perry G, Boons J, Ceuterick-de Groote C, Lübke U, Mercken M, Tabaton M, Gambetti PL, Vandermeeren M, Mulvihill P, Siedlak S, Van Heuverswijn H, Martin J-J (1991) Demonstration of a novel ncurofilament associated antigen with the ncurofibrillary pathology of Alzheimer and related diseases. Brain Res 558:43-52.

Gilbert MR, Harding BL, Hoffman PN, Griffin JW, Price DL, Troncoso JC (1992) Aluminum-induced neurofilamentous changes in cultured rat dorsal root ganglia explants. J Neurosci 12:1763-1771.

Giudice GJ, Fuchs E (1987) The transfection of epidermal keratin genes into fibroblasts and simple epithelial cells: evidence for inducing a type I keratin by a type II gene. Cell $48: 453-463$.

Goldman JE, Yen S-H, Chiu F-C, Peress N (1983) Lewy bodies of Parkinson's disease contain neurofilament antigens. Science 221:10821084.

Guitart X, Beitner-Johnson D, Marby DW, Kosten TA, Nestler EJ (1992) Fischer and Lewis rat strains differ in basal levels of neurofilament proteins and their regulation by chronic morphine in the mesolimbic dopaminc systcm. Synapsc 12:242-253.

Guru SC, Taranath Shetty K, Shanker SK (1991) Effect of chronic ethanol ingestion on phosphate content of neurofilament proteins and neurofilament associated protein phosphatase in rat spinal cord. Neurochem Res 16:1193-1197.

Harris J, Ayyub C, Shaw G (1991) A molecular dissection of the carboxy terminal tails of the major neurofilament subunits NF-M and NF-H. J Neurosci Res 30:47-62.

Haugh MC, Probst A, Ulrich J, Kahn J, Anderton BH (1986) Alzheimer neurofibrillary tangles contain phosphorylated and hidden neurofilament epitopes. J Neurol Neurosurg Psychiatry 49:1213-1220.

Hirano A (1991) Neurons and astrocytes. In: Textbook of neuropathology, 2d ed (Davis RL, Robertson DM, eds), pp 1-94. Baltimore: Williams and Wilkins.

Hof PR, Cox K, Morrison JH (1990) Quantitative analysis of a vulnerable subset of pyramidal neurons in Alzheimer's disease: I. Superior frontal and inferior temporal cortex. J Comp Neurol 301:4454.

Hollósi M, Ürge L, Perczel A, Kajtár J, Teplán I, Ötvös L Jr, Fasman GD (1992) Metal ion-induced conformational changes of phosphorylated fragments of human neurofilament (NF-M) protein. J Mol Biol 223:673-682. 
Klosen P, van den Bosch de Aguiler P (1992) Spontaneous perikaryal neurofilament phosphorylation in the septofimbrial nucleus of the rat. Neurosci Lett 139:108-113.

Kowall NW, Pendlebury WW, Kessler JB, Perl DP, Beal MF (1989) Aluminum-induced neurofibrillary degeneration affects a subset of neurons in rabbit cerebral cortex, basal forebrain and upper brainstem. Neuroscience 29:329-337.

Lawson SN, Harper AA, Harper EI, Garson JA, Anderton BH (1984) A monoclonal antibody against neurofilament protein specifically labels a subpopulation of rat sensory neurones. J Comp Neurol 228: 263-272.

Lee MK, Xu Z, Wong PC, Cleveland DW (1993) Neurofilaments are obligate heteropolymers in vivo. J Cell Biol 122:1337-1350.

Lee VM-Y, Carden MJ, Schlaepfer WW, Trojanowski JQ (1987) Monoclonal antibodies distinguish several differentially phosphorylated states of the two largest rat neurofilament subunits (NF-II and NF-M) and demonstrate their existence in the normal nervous system of adult rats. J Neurosci 7:3474-3488.

Lee VM-Y, Otvos L, Carden MJ, Hollosi M, Dietzschold B, Lazzarini RA (1988a) Identification of the major multiphosphorylation site in mammalian neurofilaments. Proc Natl Acad Sci USA 85:19982002.

Lee VM-Y, Otvos L, Schmidt ML, Trojanowski JQ (1988b) Alzheimer disease tangles share immunological similarities with multiphosphorylation repeats in the two large neurofilament proteins. Proc Natl Acad Sci USA 85:7384-7388.

Lee VM-Y, Elder GA, Chen L-C, Liang Z, Snyder SE, Friedrich VL, Lazzarini EA (1992) Expression of human mid-sized neurofilament subunit in transgenic mice. Mol Brain Res 15:76-84.

Leonard GB, Gorham DG, Cole P, Greene LA, Ziff EB (1988) A nerve growth factor-regulated messenger RNA encodes a new intermediate filament protein. J Cell Biol 106:181-193.

Levy E, Liem RKH, D'Eustachio P, Cowan NJ (1987) Structure and evolutionary origin of the gene encoding mouse NF-M, the middlemolecular-mass neurofilament protein. Eur J Biochem 166:71-77.

Manetto V, Sternberger NH, Perry G, Sternberger LA, Gambetti P (1988) Phosphorylation of neurofilaments is altered in amyotrophic lateral sclerosis. J Neuropathol Exp Neurol 47:642-653.

Marc C, Lavel M-C, Rabie A (1986) Non-phosphorylated and phosphorylated neurofilaments in the cerebellum of the rat: an immunohistochemical study using monoclonal antibodies. Development in normal and thyroid-deficient animals. Dev Brain Res 26:249-260.

Metuzals J, Robitaille Y, Houghton S, Gauthier S, Kang CY, Leblanc $R$ (1988) Neuronal transformations in Alzheimer's disease. Cell Tissue Res 252:239-248.

Miller CJ, Brion J-P, Calvert R, Chin TK, Eagles PAM, Downes MJ, Flament-Durand J, Haugh M, Kahn J, Probst A, Ulrich J, Anderton BH (1986) Alzheimer's paired helical filaments share epitopes with neurofilament side arms. EMBO J 5:269-276.

Morrison JH, Lewis DA, Campbell MJ, Huntley GW, Benson DL, Bouras C (1987) A monoclonal antibody to non-phosphorylated neurofilament protein marks the vulnerable cortical neurons in $\mathrm{Al}-$ zheimer's disease. Brain Res 416:331-336.

Mulvihill P, Perry G (1989) Immunoaffinity demonstration that paired helical filaments of Alzheimer's disease share epitopes with neurofilaments, MAP2 and tau. Brain Res 484:150-156.

Munoz DG, Greene C, Perl DP, Selkoe DJ (1988) Accumulation of phosphorylated neurofilaments in anterior horn motor neurons of amyotrophic lateral sclerosis patients. J Neuropathol Exp Neurol 47: 9-18.

Myers MW, Lazzarini RA, Lee VM-Y, Schlaepfer WW, Nelson DL (1987) The human mid-sized neurofilament subunit: a repeated protein sequence and the relationship of its gene to the intermediate filament gene family. EMBO J 6:1617-1626.

Napolitano EW, Chin SSM, Colman DR, Liem RKH (1987) Complete amino acid sequence and in vitro expression of rat NF-M, the middle molecular weight neurofilament protein. J Neurosci 7:2590-2599.

Nixon RA (1993) The regulation of neurofilament protein dynamics by phosphorylation: clues to neurofibrillary pathology. Brain Pathol 3:29-38.

Nixon RA, Sihag RK (1991) Neurofilament phosphorylation: a new Iook at regulation and function. Trends Neurosci 14:501-506.

Oblinger MM (1988) Biochemical composition and dynamics of the axonal cytoskeleton in the corticospinal system of the adult hamster. Metab Brain Dis 3:49-65.

Pachter JS, Liem RKH (1985) $\alpha$-Internexin, a $66-\mathrm{kD}$ intermediate filament-binding protein from mammalian central nervous tissues. $\mathrm{J}$ Cell Biol 101:1316-1322.

Parysek LM, Goldman RD (1988) Distribution of a novel $57 \mathrm{kDa}$ intermediate filament (IF) protein in the nervous system. J Neurosci 8:555-563.

Peichl L, González-Soriano J (1993) Unexpected presence of neurofilaments in axon-bearing horizontal cells of the mammalian retina. J Neurosci 13:4091-4100.

Perry G, Rizzuto N, Autilio-Gambetti L, Gambetti P (1985) Paired helical filaments from Alzheimer's disease patients contain cytoskeletal components. Proc Natl Acad Sci USA 82:3916-3920.

Perry G, Stewart D, Friedman R, Manetto V, Autilio-Gambetti L, Gambetti P (1987) Filaments of Pick's bodies contain altered cytoskeletal elements. Am J Pathol 127:559-568.

Perry RH, Irving D, Blessed G, Fairbairn A, Perry EK (1990) Senile dementia of Lewy body type. J Neurol Sci 95:119-139.

Pleasure SJ, Lee VM-Y, Nelson DL (1990) Site-specific phosphorylation of the middle molecular weight human neurofilament protein in transfected non-neuronal cells. J Neurosci 10:2428-2437.

Pollanen MS, Bergeron C, Weyer L (1992) Detergent-insoluble cortical Lewy body fibrils share epitopes with neurofilament and $\tau$. J Neurochem 58:1953-1956.

Poltarak M, Freed WJ (1987) Normal neuronal cell bodies of the nucleus tracti mesencephalici nervi trigemini react with antibodies against phosphorylated epitopes on neurofilaments. Exp Neurol 97 735-738.

Portier M-M, de Néchaud B, Gros F (1983/1984) Peripherin, a new member of the intermediate filament protein family. Dev Neurosci 6:335-344.

Potter HD (1975) Distribution and dynamic properties of neurofibrils. In: Proceedings of the Golgi centennial symposium (Santini M, ed) pp 167-175. New York: Raven.

Romand R, Hafidi A, Despres G (1988) Immunocytochemical localization of neurofilament protein subunits in the spiral ganglion of the adult rat. Brain Res 462:167-173.

Schmidt ML, Lee VM-Y, Trojanowski JQ (1990) Relative abundance of tau and neurofilament epitopes in hippocampal neurofibrillary tangles. Am J Pathol 136:1069-1075.

Schmidt ML, Murray J, Lee VM-Y, Hill WD, Wertkin A, Trojanowski JQ (1991) Epitope map of neurofilament protein domains in cortical and peripheral nervous system Lewy bodies. Am J Pathol 139:5365 .

Shaw G (1991) Neurofilament proteins. In: The neuronal cytoskeleton (Burgoyne RD, ed), pp 186-214. New York: Wiley-Liss.

Shaw G, Weber K (1984) The intermediate filament component of the retina: a comparison between different mammalian species. Eur J Cell Biol 42:1-9.

Shaw G, Wialski D, Reier P (1988) The effect of axotomy and deafferentation on phosphorylation dependent antigenicity of neurofilaments in rat superior cervical ganglion neurons. Brain Res 460:227234.

Sicgel SJ, Ginsbcrg SD, Hof PR, Foote SL, Young WG, Kraemer GW, McKinney WT, Morrison JH (1993) Effects of social deprivation in prepubescent rhesus monkeys: immunohistochemical analysis of the neurofilament protein triplet in the hippocampal formation. Brain Res 619:299-305.

Sima AAF, Clark AW, Sternberger NA, Sternberger LA (1986) Lewy body dementia without Alzheimer changes. Can J Neurol Sci 13:490 497.

Skalli O, Chou Y-H, Goldman RD (1992) Intermediate filaments: not so tough after all. Trends Cell Biol 2:308-312.

Steinert PM, Liem RKH (1990) Intermediate filaments dynamics. Cell 60:521-523.

Szaro BG, Whitnall MH, Gainer H (1990) Phosphorylation-dependent epitopes on neurofilament proteins and neurofilament densities differ in axons in the corticospinal and primary sensory dorsal column tracts in the rat spinal cord. J Comp Neurol 302:220-235.

Terry RD, Pena C (1965) Experimental production of neurofibrillary degeneration. 2. Electron microscopy, phosphate histochemistry and electron probe analysis. J Neuropathol Exp Neurol 24:200-210.

Toyoshima I, Yamamato A, Masumune O, Satake M (1989) Phosphorylation of neurofilament proteins and localization of axonal swellings in motor neuron disease. J Neurol Sci 89:269-277.

Ulrich J, Haugh M, Anderton BH, Probst A, Lautenschlager C, His B (1987) Alzheimer dementia and Pick's disease: neurofibrillary tangles 
and Pick bodies are associated with identical phosphorylated neurofilament epitopes. Acta Neuropathol (Berl) 73:240-246.

van den Bosch de Aguilar P, Goemaere-Vanneste J (1984) Paired helical filaments in spinal ganglion neurons of elderly rats. Virchows Arch [B] 47:217-22.

Vickers JC, Costa M (1991) Neurofilament triplet immunoreactivity in the dorsal root ganglia of the guinea-pig. Cell Tissue Res 265:159167.

Vickers JC, Costa M (1992a) The neurofilament triplet is present in distinct subpopulations of neurons in the central nervous system of the guinea-pig. Neuroscience 49:73-100.

Vickers JC, Costa M (1992b) Subpopulations of neurons in the guineapig inferior mesenteric ganglia distinguished by the differential distribution of neurofilament triplet epitopes. J Chem Neuroanat 5:417426.

Vickers JC, Costa M, Vitadello M, Dahl D, Marotta CA (1990) Neurofilament protein-triplet immunoreactivity in distinct subpopulations of peptide-containing neurons in the guinea-pig coeliac ganglion Neuroscience 39:743-759.

Vickers JC, Delacourte A, Morrison JH (1992) Progressive transformation of the cytoskeleton associated with normal aging and $\mathrm{Al}-$ zheimer's disease. Brain Res 594:273-278.
Wang S, Hamberger A, Ding M, Haglid KG (1992) In vivo activation of kainate receptors induces dephosphorylation of the heavy neurofilament subunit. J Neurochem 59:1975-1978.

Way J, Hellmich MR, Jaffe H, Szaro B, Pant HC, Gainer H, Battey J (1992) A high-molecular weight squid neurofilament protein contains a lamin-like rod domain and a tail domain with Lys-Ser-Pro repeats. Proc Natl Acad Sci USA 89:6963-6967.

Xu Z, Cork LC, Griffin JW, Cleveland DW (1993) Increased expression of neurofilament subunit NF-L produces morphological alterations that resemble the pathology of human motor neuron disease. Cell 73:23-33.

Zhang $\mathrm{H}$, Sternberger NH, Rubinstein LJ, Herman MM, Binder LI, Sternberger LA (1989) Abnormal processing of multiple protcins in Alzheimer disease. Proc Natl Acad Sci USA 86:8045-8049.

Zopf D, Hermans-Borgmeyer I, Gundelfinger ED, Betz H (1987) Identification of gene products expressed in the developing chick visual system: characterization of a middle-molecular-weight neurofilament cDNA. Genes Dev 1:699-708. 